\title{
PEDAGOGICAL IMPLICATIONS OF SOME NEGLECTED DIFFER- ENCES BETWEEN BRITISH AND AMERICAN ENGLISHES: PROBLEMS FOR WEST AFRICAN TEACHERS, EXAMINERS AND EXAMINEES
}

\author{
K. O. O. Armah \\ Department Of English \\ Kwame Nkrumah University of Science and Technology, Kumasi
}

\begin{abstract}
Our premise in this paper is that the fulcrum of pedagogy is two-fold: teaching and examining. Thus, we look at some of the differences between British and American English usage, problems in the teaching situation and how teachers and examiners could handle situations where there is a mixture of British English and American or North American English. The telos of the paper is that since the medium for nearly all examinations conducted in Ghana, and much of West Africa is the English Language, and since many Englishes appear to be competing among themselves for legitimacy and/or supremacy, there is an imperative need to ensure that examinees are not unduly disadvantaged. The paper explores aspects of four broad areas of English grammar where, in pedagogy, there appears a pronounced tendency to ignore the variant usages. The focus is on tense, vocabulary, orthography and preposition. Each of these grammatical categories has been discussed exclusively; that is, no one discussion is contingent on the other albeit they are intertwined by the broad concept of pedagogy in English. The major question that underpins our effort is: what is the teacher and for that matter the examiner to do when caught in such a linguistic labyrinth as we often are, as far as examinations are concerned? It is suggested that as much as possible fairness in evaluating student's essays should be the paramount objective of the teacher and the examiner. Thus, the paper argues that it is incumbent upon West African teachers and examiners to consciously educate themselves on the variant usages in the English language to ensure consistency and justice in teaching and evaluating student papers.
\end{abstract}

Keywords: language, examinee, pedagogy, practising teacher, examination, literacy.

\section{INTRODUCTION}

The West African Examinations Council (WAEC) has established factors or parameters for judging examination scripts as regards essays or compositions. These are four in all: Content, Organisation, Expression and $\mathrm{Me}-$ chanical Accuracy. Content refers to the relevance of the candidate's answer to the question;
Organisation refers to the appropriate arrangement of material into clearly connected paragraphs; Expression is the way the candidate has used language appropriate to the subject, and Mechanical Accuracy deals with such mechanical things in written communication as punctuation and spelling. This paper does not have in focus all the above-mentioned mechanisms 
for teaching and judging candidates as far as examinations are concerned. The paper is mainly concerned with "expression" and "orthography". Orthography falls under the above-mentioned Mechanical Accuracy. Content and Organisation appear to have universal similarities so they are not exactly in focus in this treatise.

One truism underpins our concentration on Expression and Orthography and that is that no two languages are ever the same. Since this paper's focus is on British and American Englishes it might be useful to dilate a little on why the two cognate Englishes could be described as individual languages. Hudson's (2004) discussion of whether British and American Englishes are individual languages or dialects in his widely acclaimed textbook simply titled Sociolinguistics is acceptable to this paper. According to him, the contrast between 'language' and 'dialect' is, among others, a question of prestige. For him, language has a prestige which dialect does not have and in this sense, Standard English (although an imprecise notion) "is not a dialect at all, but a language." Hudson explains that "whether some variety is called a language or a dialect depends on how much prestige one thinks it has, and for most people this is a clear-cut matter, which depends on whether it is used in formal writing." Thus, for us, owing to the huge prestige enjoyed by British English and American English as a result of scientific and technological expansions the two have become distinct languages in many senses, Gramley's (2001) impeccable view on this matter notwithstanding.

According to Gramley, “... English is a single language, and the very fact that this book (The Vocabulary of World English) is written in English - albeit with some idiosyncratic and/or local characteristics of the author - should itself be reminder enough." Indeed, the unity of English is a basic truth since users of a particular variety are able to communicate with users of other varieties. However, the idiosyncratic predispositions which define the varieties and make them individually distinct ought to be recognised in spite of the unity of the language to ensure competent and credible assessment of examination papers. Our point is that British English and American English are languages because of prestige and precisely because they are languages they have their individual identities and are therefore "separable." This aplomb is analogically buttressed by Quirk et al., (1974): "The properties of dog-ness can be seen in both terrier and alsatian (and, we must presume, equally), yet no single variety of dog embodies all the features present in all varieties of dog."

Our strategy in determining the effect on examinees of the tendency to accommodate usage of all sorts of English in academic systems, especially in non-native English-speaking environments such as West Africa was rather unorthodox. Four main approaches were designed and used. Firstly, we adopted what we choose to call the "espionage approach." We engaged in informal discussions and ordinary conversations with various interlocutors, particularly teachers in pre-tertiary schools without unclothing our objective. The aim was to capture views shorn of linguistic ornamentations and which we believed would be truly genuine and reliable. Secondly, we gave some passages which contained a mixture of British and American orthography to some second cycle teachers to mark. The passages contained both American and British orthography. We were not very successful in that regard as most of the teachers were not too eager to mark, or were not comfortable with being tested, but our aim had been to see how an examination script with a careless mixture of British and American spellings would be handled by more than one examiner. Thirdly, we sought to know the responses of students or candidates who might be inadvertently awarded low marks because of their American spellings. We did this by giving out some recurrent variant spellings to students to choose the 'correct' ones. We then asked the pertinent question: "What would you do if in comparison with your cohorts, you obtained low marks because of your inconsistency in spelling - using both British and American 
spellings?" Finally, the matter of the so-called "vanishing prepositions" or omission of prepositions in present-day English language usage was randomly discussed with some teachers using selected sentences from some newspapers. Some of those sentences have been indicated in this paper.

\section{THE SIMPLE PAST AND THE PRESENT PERFECT}

It might be rather trite to attempt a detailed discussion of the English tense in this paper. Our focus is on how the simple past tense and the present perfect tense operate in British English and American English. We are particularly concerned about the use of these two tenses as free variants in American English. Hence, we look at the possible ramifications for the examinee who is a non-native user of the English language and who is improperly exposed to such variant usages. Therefore, it might suffice for our purposes to limit ourselves to definitions of the two categories of tense rather than go into the nature of the English tense.

Quirk et al., (1974) simply say that "English has two tenses: present tense and past tense." They add that "as the names imply, the present tense normally refers to present time and past tense to past time." Defining the simple past they say that "the basic meaning of the simple past tense is to denote definite past time, ie what took place at a given time or in a given period before the present moment." They also define the present perfect as follows: "The present perfect indicates a period of time stretching backwards into some earlier time. It is past with current relevance" a point which is accentuated by Sheen (1994) who states that "current relevance is the essential semantic feature of the present perfect" and for Frazer (1990) the present perfect tense "... indicates that something began in the past and continues into the present or that it occurred at an unspecified time in the past." The foregoing definitions are simplified for us by Pryse (1984) as follows: the simple past tense is used "when we wish to say that something happened, took place and was definitely finished and completed in the past. Here there is no link with the present at all." She explains that although the present perfect often causes great confusion it is used "when we wish to show that a past action has some connection with the present. Either the result of the past action is still apparent, or something that was started in the past is still going on in the present. This tense is the link between the past and the present..." For our purposes two salient points are noteworthy here: (a) the simple past tense has no current relevance and (b) the present perfect tense links the past to the present. Indeed, these basic definitions are what would normally be fed to students in examination-oriented situations.

But the above definitions notwithstanding, Sheen (1994) states that there appears a rather worrying silence except in a few scholarly journals over the use of the simple present tense and the present perfect tense as free variants. The free variation has either been ignored or given scant attention by most prominent grammarians. Even Quirk et al., (1974) though prominent members of a cognoscenti of prescriptive grammarians (as regards standard English usage) refuse to discuss in detail the problem of this tendency of Americans to replace the present perfect with the simple past and the reasons may only be surmised. It does not appear to be a relevant or pressing linguistic issue and so there is not much effort at a systematic analysis. Thus, Sheen (1994) expresses the view that what might account for the failure of most noted grammarians, pedagogical grammars and course books to do in-depth analysis of this problem is that "the use of the simple past as a free variant of the present perfect is not regarded as good English. Therefore, perhaps such books do not wish to propagate it."

Indeed, most grammar books merely explain the two forms and leave learners to make their own choices. But, without meaning to delve into the caldron of polemics involving the prescriptive-descriptive dichotomy in the teaching of grammar, we can say that in a teaching situation the prescriptive approach is normally preferred as the descriptive approach might not be beneficial to the student. That is why Sheen 
(1994) declares that:

The free variation between the simple past and present perfect would have no relevance in such a prescriptive examination-oriented situation, in which a student would certainly be penalized for writing, for example, We finished three exercises so far, despite the fact that most North Americans would find it acceptable.

Sheen therefore proposes that "teachers in such a system should be aware of the variation in order that they be prepared to respond to the keen student who, seeing his so far simple past marked wrong, says "But I heard that in a movie last week."

Such a challenge from the keen student can come only in the classroom situation but not in the situation where examinations are conducted by external examining bodies. Examinees are never privy to their marked papers and so may never know why they failed. It is so even at the tertiary level where the teacher is also the examiner. In English-speaking West Africa the main examining body is the West African Examination Council. We find that unless the teachers who serve as examiners or markers have been sufficiently exposed to the free variant usages some examinees may be failed unjustifiably. Let us look carefully at the following sentences:

1. ...Vodafone would make GT part of an international network and that would make the company enjoy a new range of products and services, such as the mobile money transfer service (which enabled people without bank accounts to access medical services) and low cost, high quality mobile devices which would lower the cost of access to telecommunication services. (Daily Graphic, July 28, 2008 p3.)

We note that since the subject of making "GT part of an international network" has current relevance then the present perfect, has enabled, would be seen as more correct than the simple past, enabled.
2. Kenya's President Mwai Kibaki has been forced to end his independence day speech after a crowd heckled him when a protester was arrested. ( Daily Guide, World News, December 15, 2008 p5.)

The tenses has been and was are inconsistent with each other because the act of making the speech is past and gone and therefore has no current relevance. It may be more correct to say Kibaki was forced ...

From the foregoing analysis we are certain that the following examples might be marked wrong by most West African examiners:

1. I read only two of the Literature set texts so far.

2. Mr. Ibu appeared in thirty eight Nigerian movies since 1998.

3. This government did a lot in the Energy sector. ( Talking about a government which is still in power).

4. He became minister in the government since it came to power. (GBC 6pm news on the sudden death of the then Minister of Finance, Mr. Kwadwo Baah Wiredu. 24/9/2008).

5. I changed my mind; I am not attending the lecture.

6. Maame Ama is a lady I knew since five years ago in my neighbourhood. (University student essay, 2008).

7. The most wonderful thing about him is that, he adopted over ten children who are orphans. (University student essay, 2008.The adoptive parent is still alive.)

8. Woman, 88, says she overpaid land taxes since 1970. (Daily Guide, 18/10/2008. p3).

9. Mr. Tawiah is the most generous man I ever met. (University student essay, 2008)

10. Federal prosecutors charged two men with plotting a 'killing spree' against AfricanAmericans that would have been capped with an attempt to kill Senator Barack Obama ... (Daily Guide, October 29, 2008. p5). 


\section{VOCABULARY}

There is no one English language usage which is universally acknowledged as being standard and it would probably amount to a weird prognostication to suggest that there could ever be one. Hence, since there are now various Englishes but not just British English, then there are various Standard Englishes defined according to the peculiar linguistic nuances of particular peoples. Thus, we have, among others, the American Standard English, the Singaporean Standard English, the Filipino Standard English and the Australian Standard English which according to Quirk et al., (1974) dominates the Antipodes,

Indeed, American Standard English is described by Corder et al., (1985) as "an idiolect or dialect that has been modified to produce a uniformity in sound, a consistency with grammatical standards traditionally taught in English and American schools, and a vocabulary that can be shared by people in different places at different times." For Corder et al, American Standard English is Edited American English. They see it as the version of the English language which is "associated with schools, good newspapers, good books, and good public speakers."

Generally, however, the term Standard English describes how the majority of educated people use the English language. While we are ambivalent about tagging any particular English language usage as Universal Standard English, we nonetheless think that Standard English is what would normally be acknowledged in academia as being scholarly. This is a universal fact which explains why the educated Canadian or American would have no difficulty understanding a scholarly paper by a British. The contrasts are not as pronounced as, for example, the contrast between London Cockney, Yorkshire English and Standard English. But, although the differences between Canadian Standard English, American Standard English, and British Standard English are not very significant there are enough differences to warrant due cognisance of the interests of non-native
English-speaking examinees in this universal language; else would there be anything like, for example, speaking with snobbish affectation by some English-speaking West Africans. Often, people returning, sometimes from very brief sojourn in the Americas would speak with curious American accents which tend to befuddle 'non-been-tos.' Such returnees are derided rather than admired, just as free usage of some vocabulary in West Africa tend to make listeners look askance at the users. Our point is that American English and British English have sufficient contrasts to make them different. Indeed, as Corbin et al., (1965) put it, "Englishmen, Canadians, and Americans speak English; but they do not speak exactly the same kind.” In view of this truism, the following table illustrates the difference.

\section{Table 1: AmE and BrE vocabulary}

\begin{tabular}{ll}
\hline American English & British English \\
\hline private school & public school \\
shoe & boot \\
telephone booth & call-box \\
truck & lorry \\
bonnet/hood & bonnet \\
boob & boob \\
railroad & railway \\
tail-pipe & exhaust pipe \\
handbag & purse \\
\hline
\end{tabular}

As part of our investigations we put forward some of the pairings above to some of our interviewees, particularly, University Teaching Assistants to see if a mixture of British and American vocabulary could create any problems. We did not suffer to understand the implications for the examinee if the examiner is not very conversant with variant usages as far as British English and American English are concerned. One of our questions was: What meanings could there be (for the American, the British or the Ghanaian) in the following sentences?

i) I don't speak good English because I attended a public school.

ii) She excelled because she attended a private school. 
The BBC English Dictionary (1992) says of public schools inter alia:

1. In Britain a public school is a private school that provides secondary education. Parents have to pay fees to send their children to a public school.

2. In the United States, Australia, and some other countries, a public school is a school that is supported financially by the government.

As regards private school the dictionary says: "A private school is a school which is not supported financially by the government and which parents have to pay for their children to go to. Clearly, for the American the following would be the meanings of sentences $i$ and ii above:

1. The first speaker attended schools owned by government.

2. The second speaker attended schools owned by private people.

These must be very interesting interpretations to the West African learner of the English language. In fact, for the Ghanaian, the first speaker's poor performance was because he attended government schools while the second speaker's excellence was because she attended privately owned schools which in Ghana are generally perceived as being superior to public schools in terms of academic performance. Thus, simply put, the Ghanaian is in agreement with the American that a public school belongs to government. Intriguingly, although the Ghanaian learns basically British English his understanding is at variance with the British in this case.

Similarly, a Ghanaian schoolboy may not understand why his father would buy a pair of boots for him instead of a pair of shoes! After all boots, such as the Wellington boots are not worn to school; they are worn by artisans and farmers. Nor would the Ghanaian make a call in a call-box but in a telephone booth. Even more interesting is the fact that the Ghanaian would normally not see a truck as being the same as a lorry. For most Ghanaians a truck is normally used to carry cargo while a lorry is used mainly to carry passengers. Again, just as certain Americanisms could generate an amusing effect in some British ears so would it be amusing if an American visitor to Accra should tell their host, "If we can't get a cab let's join the truck." And you would probably have nothing done for you if you should tell the Ghanaian 'wayside fitter' to fix your tail-pipe for you instead of the exhaust pipe. Indeed, not many Ghanaian drivers would pull up at filling stations to buy gasoline; they would buy petrol!

To conclude this section, we think the two words, boob and bonnet cited above are worth commenting on. In British English the word boob is used (offensively though) to describe a woman's breasts or a mistake made by another person. In American English, however, the word normally describes someone who is seen as a fool. So, what could the sentence: These are fantastic boobs mean for the non-native user of the language who has been exposed mainly to British English? As regards the word bonnet an interesting observation is made by Akmajian et al (1995). They first observe that meanings vary "across dialects and across individual speakers." Illustrating this they say that the word bonnet refers only to a hat in American English "whereas in British English it can refer to the hood of a car." They conclude: "Hence, for a word such as bonnet we cannot isolate a single meaning valid for all forms of English; rather, our discussion of the meaning of the word will be relative to a specific dialect of English," (and perhaps context too.) In the educational systems of English Speaking West Africa, although British English is the main medium of instruction the necessity to train several teachers abroad for tertiary education has meant free usage of various Englishes, especially the British and the American. This situation leaves the non-native learner confused since the use of one form might be acceptable to one examiner but unacceptable to another. We saw this when we gave an exercise to some students. One of the questions was as given below:

From the alternatives $A$ to $D$ choose the answer which is nearest in meaning to the underlined word or expression. 
One of the questions was:

"Suddenly, she stopped the car, grabbed the lizard and the bonnet and threw them into the bush." A bonnet is ...

a) a vehicle's back

b) a metal which covers a car engine

c) the hat of a female

d) the heart of a male

No one chose alternative $\mathrm{C}$ though one person apparently deceived by the word 'vehicle' thought a bonnet was "a vehicle's back!"

Clearly, the West African teacher of English faces a myriad of linguistic problems. What the foregoing analyses tell us is that as far as examinations are concerned we cannot ignore the distinct senses of certain words and expressions as far as British English and American English are concerned.

ORTHOGRAPHY AND VARIANT SPELLINGS Just like vocabulary, several grammar books recognise the existence of variant spellings but most appear to shun definite prescription as to which are acceptable. Some even go as far as to instruct that people should choose the form of spelling they find as being appropriate to their subject and style. But we are interested in what Corder et al (1985) say in this regard. According to them:

Most people writing today, and certainly anyone who has difficulty with spelling, will ordinarily prefer ... American rather than British spellings. For the spelling of proper names ... and for direct quotation ...British spelling should be followed, but in other situations the American forms should be used.

This appears a rather confusing postulate not only for the practising teacher but also for the student (in the examination-oriented situation.) We find that for Corder et al inconsistency in spelling and for that matter usage even in a single composition are immaterial and therefore acceptable and the student is at liberty to use any of the variant spellings and constructions. But to the confusion of non-native users of the
English language, Wood (1974) makes a declaration which puts him in contretemps with Corder et al. According to him:

Certain words and constructions have been described as Americanisms. This does not necessarily mean that they are bad English. Many Americanisms (though not all) are good English ...in America.

He adds, and that is this paper's major concern, that:

... where British and American usage differ, British writers and speakers should follow the British idiom, not the American. The foreign student is at liberty to decide for himself which he will adopt, or to let his teacher decide for him.

Fundamentally, what it means is that where usage differs, Wood's virtual edict is that British writers and for that matter British English learners must follow the British idiom. For Corder, however, where there is a difficulty with orthography, especially as regards proper names, the American spelling should be the option but British spelling could be used in other situations. This is an intriguing and a confusing linguistic matrix for the non-native user of the English language. Then again, the teacher is to act as the decider where there is a problem with spelling. How is the teacher to decide, especially, in the situation where the spellings are inconsistent but correct nonetheless?

A careful study of trends in education in Ghana and English-speaking West Africa shows that there is a preponderant usage of British rather than American English. Indeed, books written in British English dominate the educational system and there is virtually nothing like American English in pre-tertiary institutions in Ghana. The classroom teacher of the English language in Ghana would use books written in British English and for that matter books with British spellings and grammar but hardly typically American books. This means that the teachers are themselves inclined to British Eng- 
lish usage and therefore their encounter with American English is largely accidental. Consequently, most teachers, especially those in our basic schools may not be able to understand the prescriptions of Corder et al and in such a situation the examinees might ultimately be the patient sufferers. Pedagogically, therefore, there appears a definite need for consistency in language usage in our schools otherwise our examinees would be faced with debilitating nuanced choices to their detriment. To demonstrate the difficulty for both teacher and student we provide below a few examples of what we call nuanced choices. Going by Corder's rule, the examinee can use any one word in any of the following pairings:

Table 2: AmE and BrE variant spellings

\begin{tabular}{ll}
\hline American English & British English \\
\hline center & centre \\
labor & labour \\
pajama & pyjama \\
honor & honour \\
favor & favour \\
mold & mould \\
fulfill & fulfil \\
advise & advice/ advise \\
candor & candour \\
insure & ensure \\
\hline
\end{tabular}

It is not the suggestion of this paper that the above variant spellings are incorrect or are unknown to averagely educated people. What is at issue is that a composition which contains a free mixture of any of the pairings or spellings above cannot be considered serious. The inconsistency is not likely to please the teacher or the examiner and the candidate might be penalised. Some linguistically ill-equipped examiners may see some of the spellings as incorrect. Our experiments proved this to be a fact. For example, after examining a group of final year students some of whom had appeared oblivious of the existence of some of the variant spellings we gave three sentences, two by Americans and one picked from a Ghanaian newspaper, to a few pre-tertiary teachers to look at. The first was from Graves (1976) and the second from Christman (1976).

1. The reason for studying sentence patterns, it should be understood, is not to insure that every paragraph the student writes ... include a variety of sentence patterns.

2. Saint Peter's College is trying to insure that all its freshmen learn to write clear, readable prose before they go further in college.

3. It is the responsibility of the Electoral Commission to ensure that the nation has a credible voters' register.

Like the final year students of English mentioned earlier, none of the respondents retained the word insure in the first two sentences. They changed insure to ensure and it is likely that the teachers involved would have marked insure as incorrect in an examination. In the same exercise most interviewees rejected advise used as a noun in such a sentence as "If he'll not listen to your advise then I advise you to ignore him" because they seemed unaware that the word is both a noun and a verb in American English but only a verb in British English where the noun form is advice.

\section{ELLIPSIS OF PREPOSITION}

This is an area where some teachers appeared unsure whether sentences such as They came here Sunday should be accepted in the classroom situation or by examiners. Some of the teachers thought there was an unacceptable tendency to omit the preposition and also felt that when the preposition appeared omitted the construction was often American. But there is not much difference in usage of the preposition in the two languages. As we would point out presently even where they show differences it is largely semantic. In this section we seek to show when the so-called omission is acceptable. In our attempt to answer the question as to when usage of the preposition is or is not necessary we relied principally on Quirk et al and Gramley with our main focus on the preposition of time. Our apparent parochial predisposition to selectivity is informed by Gramley's 
(2001) true declaration that "prepositions are surely one of the most difficult aspects of English for non-native speakers to learn." That being so, then there is the need to handle this lexically and functionally essential area carefully in order not to confuse the non-native speaker of the language.

For some of our respondents, the following sentences culled from the foreign news pages of a Ghanaian newspaper are American because of the 'missing' preposition:

1. A 7.1 magnitude earthquake struck the South Pacific Islands of Tongo Sunday, the US Geological Survey reported. (Daily Guide, October 20, 2008. p5)

2. The newspaper said Sarkozy reported the theft last month ... (Daily Guide, October 20, 2008. p5)

3. A SUSPICIOUS fire devastated the church attended by Alaska Governor and former vice presidential candidate Sara Palin Friday night in her hometown Wasilla ... (Daily Guide, December 15, 2006, p5).

4. "We have no idea what caused it" the Rev Larry Kroon of the Wasilla Bible Church said Saturday adding that investigators were considering arson and other possible causes. (Daily Guide, December 15, 2008. p5).

We observe that sentences which do not contain prepositions are normally informal and therefore more usual, hence their preponderance in newspaper reports. What may confuse some examiners and examinees alike is that where the preposition of time is missing "the temporal adjunct takes the form of a noun phrase" instead of a prepositional phrase. In other words, when the preposition of time is omitted we apparently have a noun phrase rather than a prepositional phrase as the temporal adjunct. In such a situation, however, the teacher or examiner has to be mindful that the apparent noun phrase is semantically prepositional. In our first example above, therefore, although Tango Sunday definitely reads like a noun phrase it is prepositional because the preposition of time (on) is understood to be part of the meaning of the supposed noun phrase. Our example could also have read Tango last Sunday or even Tango on last Sunday.

The words last, next, this and that are deictic or 'pointing' words as noted by Quirk et al., (1974). What teachers need to note is that it is allowable to omit the preposition of time before deictic words. So, the sentence, Sarkozy reported the theft last month is correct; so is the sentence, Sarkozy married Monday. Indeed, some sentences may have deictic words as an element of their meaning thereby necessitating the omission of the preposition of time. For example: (a) She called yesterday. (b) The match will be played tomorrow. Here, the deictic words last and next are understood elements of the meaning of (a) and (b) respectively. As noted early on the preposition of time may be absent before nouns which have deictic words as an element of their meaning. Thus, the following words of Quirk et al., (1974) are noteworthy: "In AmE and in very informal BrE, the omission of the temporal preposition goes further; one frequently hears sentences such as I'll see you Sunday in which the preposition on is omitted before a day of the week standing on its own." They also note that "Another type of omission (characteristic of AmE) is in the initial position preceding a plural noun phrase: Sundays we go into the country." Teachers may also note that the preposition for is often absent in sentence constructions such as (a) The police trailed him six years. (b) "For" a lot of the time we just lay on the beach. (Quirk et al). In these sentences, six years and a lot of the time are phrases of duration and with such phrases the preposition for is often omitted.

Finally, we need to refer to two important situations where a preposition may or may not be used. First is when we have deictic phrases which refer "to times at more than one remove from the present." The following are examples:

a) the day before the elections

b) the January last (Quirk et al, 1974: p319)

c) Monday week (BrE, Quirk et al, 1974: p319) 
In sentences these phrases could read as follows: a. (on) the day before the elections; $b$. (in) the January before last; c. (on) Monday week. Quirk et al indicate, though, that $O n$ Monday week is BrE while Americans would normally omit in from the phrase in the January before. The second situation where the omission of the preposition is optional is when we have phrases "which identify a time before or after a given time in the past or future." In this regard the following alternatives are acceptable:

a) We met on the following week. We met the following week.

b) They married on that day. They married that day.

c) The armed robber was arrested at the following weekend.

The armed robber was arrested the following weekend

But, as earlier hinted we could have different prepositions in similar constructions in British English and American English which may nonetheless be the same semantically. The following examples taken from Gramley (2001) would illustrate this:

Table 3: BrE and AmE differences in prepositions

\begin{tabular}{ll}
\hline British English & American English \\
\hline apart from & same or aside from \\
different from & same or different than \\
on behalf of & same or in behalf of \\
Monday to Friday & same or Monday through Friday \\
on Tuesdays & same or Tuesdays \\
We haven't seen & We haven't seen him in \\
him for two weeks. & two weeks. \\
on top of & same or atop \\
\hline
\end{tabular}

We agree with Gramley (2001) that between British English and American English "only a few differences are significant in the sense that they mark meaning distinctions." He illustrates this with the examples round and around and says that BrE makes a distinction which is missing in AmE. According to him, in both $\mathrm{AmE}$ and BrE around is used for "scattered distribution in an area." However, in describing a "circular movement," AmE would freely use around while BrE would use round. Although there may not be many significant differences in the usage of the preposition the possible variant forms indicated above merit consideration on the part of, especially, examiners; otherwise examinees might suffer for writing:

a) Mine is different than yours instead of Mine is different from yours.

b) She did it in her husband's behalf instead of She did it on her husband's behalf.

c) She hasn't been here in four years instead of She hasn't been here for four years.

d) The interviews would be held from Monday through Friday instead of The interviews would be held from Monday to Friday.

For the non-native user of British English the different prepositions used in the similar sentences above do not necessarily have paradigmatic relationships and that may be a serious source of confusion.

\section{CONCLUSION}

Americanisms versus Britishisms or Briticisms and indeed comparison of American English and British English are subjects which have been extensively studied. Patridge (1964) directs those who wish to compare American and British Englishes to such great scholars on the subject as John W. Clark, H.W. Horwill, G.P. Krapp, G.H. McKnight, H.L. Mencken and A.W. Read. This paper does not go their way. Our concern has been to see the extent to which the learner and the instructor could be affected and influenced when the variant usages are ignored in pedagogy. This paper has been an attempt at unraveling some of the oft-ignored difficulties learners and teachers of the English language face as far as examinations are concerned. Our research shows that without due cognisance of the factors (no matter how few or seemingly insignificant) which differentiate British and American usages non-native users of the English language could be confronted with disturbing nuanced choices. Our aim therefore has not been to postulate total separa- 
tion of British and American Englishes; for, we cannot imagine the magnitude of such rabidity. In fact, we are in agreement with Akmajian et al (2001) that "in reality, a variation in language is so pervasive that each language is actually a continuum of languages from speaker to speaker, and from group to group, and no absolute lines can be drawn between different forms of a language."

But we find that the non-recognition of the variant usages only leads to a "strained and grotesque" style in speech and writing. The question is what the examiner has to do when a composition is "infested," as it were, with British and American sentence patterns, spellings, usages and idioms? It is to answer such a question that we have tried in this paper to examine some of the recurrent areas where variant usages operate freely. The WAEC and teachers of English in West Africa have a lot to do. This paper's position is that there are a lot of West African teachers and learners who may not be aware of the variant usages or are simply indifferent. In the examination-oriented situation there is the need for consistency without which the examinee might suffer. There is no way we can stop varieties of the language from assailing us, given our English language-driven globalised world. Thus, we think painstaking study of American English is necessary. This could be subsumed in language study in our schools. That way, students would be able to see the differences and make good choices. We also suggest that during conference marking the WAEC should orientate examiners towards a good comprehension of the variant usages. This can be done by subsuming various alternative usages in marking schemes, especially, in evaluating English language essays or compositions. Finally, since our concern is the need to avoid being unjust to examinees because of our inadequate awareness of variant usages the following words of Graves (1976) are absolutely in order:

Most English teachers recognise the rampant inconsistencies in evaluating student papers, but surprisingly few seem to realize or care that such inconsistencies represent a gross injustice against a vast number of young people.

\section{REFERENCES}

Akmajian, A., Demers, R.A., Farmer A.K. and Harnish, R.M. (2003). Linguistics, An Introduction to Language and Communication, New Delhi, Prentice-Hall of India Private Limited.

BBC English Dictionary (1992) London, BBC and Harper Collins Publishers Ltd.

Corbin, R.K., Perrin, P.G. and Burton E.W. (1965). Guide to Modern English, Toronto, Scott, Freeman and Company and W.J. Gage Limited.

Corder, J. W. and Ruszkiewicz, J.J. (1985). Handbook of Current English, Glenview, Illinois, London, England, Scott, Foreman and Company.

Christman, E. (1976). What means? Who says? Teaching College Freshmen to Write Clearly. In: Graves, R.L. (Editor) Rhetoric and Composition, A sourcebook for Teachers, Rochelle Park, New Jersey, Hayden Book Company Inc.

Frazer, C. L. (1990). The Beacon Workbook, Boston. Mifflin Company.

Gramley, S. (2001). The Vocabulary of World English, London, New York, Arnold, Copublished in the United States by Oxford University Press Inc.

Graves, R. L. (1976). A Strategy for Teaching Sentence Sense. In: Graves R.L. (Editor) Rhetoric and Composition, A Sourcebook for Teachers, Rochelle Park, New Jersey, Hayden Book Company Inc.

Hudson, R.A. (2004). Sociolinguistics, Cambridge, Cambridge University Press.

Patridge, E. (1964). Usage and Abusage, Harmondsworth, Middlesex England, Penguin Reference Books. 
Pryse, B.E. (1984). English Without Tears, Glasgow, William Collins Sons and Co. Ltd.

Quirk, R., Greenbaum, S., Leech, G. and Svartvik, J. (1974). A Grammar of Contemporary English, London, Longman Group Limited.
Sheen, R. (1994). A Neglected Difference between British and American English. Volume 32, Forum, English Teaching Forum.

Wood, F.T. (1974). Current English Usage, A Concise Dictionary, London, Basingstoke, The Macmillan Press Ltd. 